\title{
PENINGKATAN KAPASITAS WARTAWAN SISWA DALAM PENERBITAN MAJALAH SEKOLAH DI SMP MUHAMMADIYAH PK AL-KAUTSAR KARTASURA
}

\author{
Agus Triyono ${ }^{1}$, Dzikrina Aqsha Mahardika, Lita Rengga Asmara, Verlandy Donny Fermansah \\ Program Studi Ilmu Komunikasi \\ Fakultas Komunikasi dan Informatika, \\ Universitas Muhammadiyah Surakarta \\ Email1': agus.triyono@ums.ac.id
}

\begin{abstract}
ABSTRAK
Majalah sekolah menjadi sarana yang sangat penting bagi institusi bukan hanya sebagai media informasi, akan tetapi sekaligus juga media promosi sekolah. Disamping itu, majalah tersebut juga dapat menjadi wadah bagi siswa untuk berlatih menulis. Namun demikian, ketrampilan menulis pelajar Indonesia masih banyak terkendala dikarenakan keterbatasan media dan fasilitas penunjang di sekolah. Untuk itu, pemberdayaan wartawan siswa dirasa sangat perluh untuk beberapa sekolah yang belum memiliki majalah sekolah sendiri. SMP Muhammadiyah PK Al-Kautsar Kartasura adalah salah satunya. Sekolah yang baru berdiri 2010 ini memiliki 95 siswa. Majalah sekolah dapat menjadi sarana menampung kreativitas siswa dalam menulis dan menyalurkan ide-ide kreatif mereka. Selain itu, Majalah sekolah bisa menjadi salah satu media komunikasi antarelemen sekolah, mulai siswa, guru, karyawan sekolah, hingga kepala sekolah. Pembuatan majalah sekolah yang diberi nama Al-Kautsar ini dirasa akan dapat menjadi salah satu media promosi yang efektif dalam meningkatkan peminat siswa baru. Metode yang dilakukan dalam pendampingan antara lain dengan memberikan pelatihan, penugasan, pendampingan, dan kunjungan ke instansi media cetak di Solo Raya yang berhubungan dengan dunia jurnalistik. Kegiatan pemberdayaan wartawan siswa yang dilakukan selama 5 bulan ini memberikan kontribusi yang baik dalam mengelola potensi siswa-siswi di bidang Jurnalistik. Sebelum diadakan pemberdayaan potensi siswa siswi yang tergabung dalam Tim Jurnalistik belum tersalurkan dengan baik, namun setelah diadakannya pendampingan potensi mereka kini dapat diasah dan dikembangkan. Disamping itu, pada akhir program pengabdian ini berhasil dibuat Majalah Al Kautsar.
\end{abstract}

Kata kunci: Majalah sekolah, pemberdayaan, wartawan siswa, jurnalistik.

\begin{abstract}
The school magazine becomes a very important means for institutions not only as a medium of information, but at the same time also the media promotion of the school. In addition, the magazine can also be a facility for students to practice writing. Indonesian students nowadays still find some problems in developing their writing skills caused by lack of media and school facilities. For that reason, school magazine mentoring in some certain schools can be an effective way to solve that problem. SMP Muhammadiyah PK Al-Kautsar Kartasura is one of these schools that needs it. This school was built 5 years ago and now has 95 students. School magazine can be
\end{abstract}


a media to improve writing skill for students. In other hand, it can also be a media to communicate between students, teachers, employees, and even the headmaster. This school magazine is named after the school name, Al-Kautsar. It can be an effective media for school promoting as well. Methods that are used during the mentoring are couching, assignments giving, mentoring, and visiting some media institutions in Solo City. These methods are all related to journalism field. After 5 months mentoring students who joined Jurnalistic Team showed many postive developments. Now they have school magazine as a media to improve their skills and interest in journalist. In the end of the program, SMP Al Kautsar able to produce their own magazine in 2015.

Keywords: School magazine, mentoring, student journalist, journalism.

\section{PENDAHULUAN}

Dari sisi menulis, kemampuan siswa di Indonesia belum cukup memuaskan. Namun demikian, disisi yang lain ketika ada pelajar yang mempunyai minat untuk menulis sering kali terkendala atas ketiadaan fasilitas yang mampu menampung dan mengakomodir ideide mereka. Meskipun saat ini bisa dikatakan bahwa perkembangan internet dianggap mampu mengakomodasi kemampuan menulis, namun tidak semua wilayah di Indonesia bisa terhubung dengan jaringan internet (Saputra, 2015).

Sebagai salah satu solusi untuk mengatasi keterbatasan media yang menampung tulisan siswa tersebut adalah dengan memanfaatkan majalah dinding maupun majalah sekolah (Dewi, 2013). Melalui media ini, potensi dari siswa masih dapat terus diasah sehingga tulisan yang dibuatpun juga semakin berkualitas. Tidak hanya itu, keberadaan majalah sekolah juga dapat dianggap sebagai sarana komunikasi antar elemen yang ada di sekolah, baik antara guru dengan siswa, karyawan hingga kepala sekolah selaku top management di sekolah. Beragam informasi bisa saling didapat dan dibagi melalui media tersebut. Sebagai contoh misalnya, seorang guru Matematika dapat menulis mengenai pembelajaran sebuah tema tertentu dengan cara yang mudah dan menyenangkan. Tulisan yang demikian, apalagi ditambah dengan ilustrasi tentu diharapkan mampu membuang stigma di kalangan siswa bahwa Matematika adalah mata pelajaran yang sulit.

Dengan tulisan tersebut, maka diharapakan ada komunikasi antara guru dengan murid. Secara lebih lanjut, siswa dapat bertanya mengenai hal-hal yang belum dijelaskan secara detail dalam tulisan tersebut. Tidak hanya itu, kepala sekolah juga dapat berinteraksi secara informal melalui tulisan semisal ulasan mengenai motivasi belajar untuk siswa maupun guru untuk mengajar.

Keuntungan yang cukup penting dalam penerbitan majalah sekolah adalah dapat digunakan sebagai media promosi. Sudah menjadi pemahaman umum bahwa majalah sekolah mempunyai fungsi promosi yang cukup ampuh untuk mengenalkan sekolah (Miyono, 2011). Pembaca yang berasal dari luar, dapat mengetahui kelebihan maupun keunggulan yang dimiliki sekolah tersebut. Tidak hanya itum pembaca juga dapat memahami program apa yang sudah dijalankan oleh sekolah untuk meningkatkan kualitas siswa dan gurunya. Pada akhirnya, pembaca dapat menilai bagaimana kualitas sekolah yang bersangkutan.

Tujuan dari dilakukannya pemberdayaan wartawan siswa ini adalah untuk mengasah bakat siswa-siswi dalam bidang jurnalistik, yang meliputi: teknik penulisan berita, teknik fotografi jurnalistik, dan teknik mendesain layout majalah secara sederhana (Hidayati, 2014). Setelah pemberdayaan ini, diharapkan siswa-siswi dapat menerapkan ilmu jurnalistik yang telah mereka. Mereka diharapkan mampu memproduksi majalah sekolah secara mandiri dan konsisten, yang tentunya masih dalam pengawasan pihak guru dan juga pelaksana. Majalah sekolah ini 
diberi nama Al-Kautsar, sesuai dengan nama sekolah tempat pengabidan ini dilaksanakan.

Majalah Al-Kautsar ini merupakan majalah perdana SMP Muhammadiyah PK Al-Kautsar Kartasura yang akan terbit secara periodik, satu kali dalam satu bulan. Desain majalah dan layout-nya dibuat semenarik mungkin, agar menarik perhatian pembaca. Majalah yang memiliki tebal 40 halaman ini mengambil tema Ramadlan, karena publikasi perdananya akan dilaksanakan pada Juni 2015 untuk menyambut Bulan Ramadlan.

\section{METODE}

Berdasarkan hal tersebut, pada pengabdian kali ini, pelaksana melakukan kerja sama dengan SMP Muhammadiyah PK Al Kautsar yang berada di Jl. Cendana I, Gumpang RT2/3, Kartasura, Jawa Tengah. Kerjasama yang dilakukan adalah dengan melakukan pemberdayaan wartawan siswa dalam pembuatan majalah sekolah kepada siswa-siswi yang tergabung dalam ekstrakurikuler jurnalistik.

Pertimbangan dalam memilih sekolah ini adalah disebabkan usia sekolah yang masih baru, yaitu sekitar lima tahun. Dengan usia yang demikian, jumlah siswa juga masih terbatas, yakni 95 siswa. Untuk itulah pelaksana memilih sekolah tersebut, agar membuat pembelajaran tentang penulisan sekaligus sebagai media promosi. Dengan demikian, jumlah siswa juga dapat mengalami peningkatan.

Pemberdayaan dilakukan selama lima bulan, yaitu mulai 24 Januari 2015 hingga 26 Mei 2015. Siswa-siswi yang tergabung dalam Tim Jurnalistik, akan diberikan pelatihan selama satu jam, dengan satu kali pertemuan dalam satu minggu. Pada kesepakatan awal, kegiatan pemberdayaan dilaksanakan pada hari Sabtu pukul 13:00 sampai 14:00 WIB, namun dikarenakan adanya perombakan jadwal ekstrakurikuler dari pihak sekolah, maka kegiatan dilaksanakan setiap hari Jumat pukul 14:00 sampai 15:00 WIB. Anggota yang tergabung dalam Tim Jurnalistik sebanyak 11 siswa yang terdiri dari siswa kelas 7 dan 8 .
Pendampingan pembuatan majalah sekolah ini dilakukan dengan beberapa cara, antara lain:

a. Pelatihan

Selama masa pendampingan, Tim Jurnalistik diberikan pengarahan mengenai teknik-teknik jurnalistik yang baik dan benar, pelatihan fotografi jurnalistik, serta cara mendesain layout majalah semenarik mungkin. Lebih lanjut, tim pelaksana juga memberikan pelatihan yang terkait dengan wawancara kepada nara sumber.

\section{b. Penugasan}

Selain mendapatkan materi dari pelatihan sebagai mana tersebut diatas, tim pelaksana juga memberikan penugasan kepada Tim Jurnalistik selaku mitra. Kegiatan penugasan dilakukan dengan meminta Tim Jurnalistik untuk melakukan sebuah peliputan dengan tema yang sudah ditentukan. Dalam penugasan tersebut, mitra juga dipantau oleh tim pelaksana agar tugas yang diberikan dapat dijalankan dengan maksimal.

Majalah perdana sebagai hasil pendampingan ini mengangkat tema Ramadlan. Hal tersebut juga dikarenakan peluncuran majalah ini akan dilaksanakan pada bulan Juni, untuk menyambut Bulan Ramadlan.

\section{c. Pendampingan}

Pada saat mengerjakan tugas untuk melakukan peliputan, Tim Jurnalistik didampingi oleh pelaksana. Pendampingan tersebut dilakukan secara intensif dengan diskusi dan rapat koordinasi untuk mendapatkan naskah maupun tulisan yang bagus dan layak. Pendampingan juga dilakukan dalam pembuatan ISSN yang diajukan ke PDII LIPI di Jakarta.

d. Kunjungan ke media cetak di wilayah Solo Raya

Dengan kegiatan kunjungan, Tim Jurnalistik dapat mempelajari berbagai informasi terkait dengan dunia jurnalistik. Seperti perkembangan media, sejarah jurnalistik di Indonesia, pelopor Jurnalistik Indonesia, dan masih banyak hal yang mereka pelajari saat melakukan kunjungan. mempunyai gambaran tentang proses 
produksi yang berlangsung di sebuah penerbitan. Adapun media massa yang akan dikunjungi adalah Solo Pos dan Joglo Semar. Disamping itu, pelaksana juga akan mengajak mitra untuk berkunjung ke sekolah-sekolah yang dianggap mempunyai media penerbitan yang sudah berjalan dengan baik.

\section{HASIL DAN PEMBAHASAN}

Target yang diharapkan dari pemberdayaan wartawan siswa dalam pembuatan majalah sekolah ini antara lain:

a. Tim Jurnalistik dapat menulis berita sesuai dengan teknik penulisan yang mengandung unsur $5 \mathrm{~W}+1 \mathrm{H}$.

b. Tim Jurnalistik dapat mengoperasikan kamera DSLR dan menghasilkan fotofoto sesuai dengan keperluan informasi pada majalah.

c. Tim Jurnalistik dapat mendesain layout majalah semenarik mungkin.

d. Tim Jurnalistik mampu menjaga eksistensi majalah Al-Kautasar.

Setelah periode kegiatan pemberdayaan berakhir, pelaksana masih akan tetap bekerjasama dengan pihak sekolah untuk melakukan kegiatan tersebut. Hal ini dilakukan agar siswa-siswi yang tergabung dalam Tim Jurnalistik dapat menggerakan majalah sekolah mereka secara konsisten, dan agar potensi Majalah Sekolah Al-Kautsar dapat terus dikembangkan.

Sebelum dilakukan pemberdayaan wartawan siswa dalam pembuatan majalah sekolah, siswa-siswi telah memiliki media untuk menyalurkan bakat menulis mereka melalui majalah dinding. Namun konten yang mereka tulis di majalah dinding ini hanya mereka dapatkan dengan mengambil sumber dari internet, sehingga potensi menulis mereka tidak dapat dikembangkan dengan majalah dinding (Wiastra, Rasna, \& Astika, 2015). Setelah dilaksanakan pemberdayaan, siswa-siswi Tim Jurnalistik telah dapat megumpulkan informasi yang mereka dapatkan di lapangan, kemudian mengolah informasi tersebut menjadi tulisan yang memiliki nilai berita. Selain itu, dalam proses pemberdayaan mereka juga diajarkan untuk menguasai teknik fotografi dan juga pembuatan layout majalah.

Kegiatan pemberdayaan dilaksanakan di ruang kelas 7 SMP Muhammdiyah PK AlKautsar Kartasura. Pada setiap pertemuan, pelaksana akan menyampaikan materi jurnalistik yang telah disusun sebelumnya. Selama satu jam, pelaksana menjelaskan materi dan kemudian memberikan tugas, agar mitra dapat langsung menerapkan materi yang telah disampaikan. Selain itu, setelah usai jam pelatihan, siswa-siswi juga akan mendapatkan pekerjaan rumah yang harus dikumpulkan pada pertemuan di minggu berikutnya.

Selain pelatihan di dalam kelas, Tim Jurnalistik juga memiliki agenda outting class untuk mengunjungi Monumen Pers Nasional dan Kantor Berita Joglo Semar. Tujuan dari diadakannya agenda tersebut adalah untuk menambah wawasan dan ketertarikan mereka di bidang jurnalistik.

Dalam proses pembuatan majalah sekolah, ada beberapa tahapan yang berhasil dilaksanakan oleh tim pelaksana. Kegiatan yang dilakukan tersebut antara lain :

\section{Pelatihan}

Sesuai kesepakatan dengan mitra, maka pelatihan dilaksanakan setiap hari Jumat jam 14.00-15.00 dengan jumlah peserta 11 orang terdiri dari kelas 7 dan 8 .

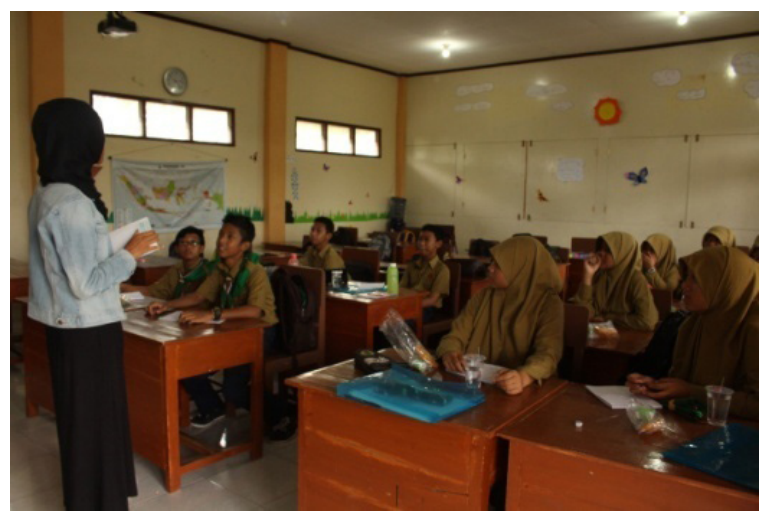

Gb. 1. Mitra sedang mengikuti pelatihan Jurnalistik.

Selama pelatihan berlangsung, mitra (tim jurnalistik) mendapatkan berbagai macam materi yang terkait dengan jurnalistik 
dalam rangka pembuatan majalah sekolah.

Materi-materi yang disajikan tersebut antara

lain:

Tabel 1. Materi Pelatihan

\begin{tabular}{|c|c|}
\hline Materi & Kisi-kisi \\
\hline $\begin{array}{l}\text { Dasar-Dasar } \\
\text { Jurnalistik }\end{array}$ & $\begin{array}{l}\text { Membahas dasar-dasar menulis berita berkaitan dengan piramida } \\
\text { terbalik, rumus } 5 \mathrm{~W}+1 \mathrm{H} \text { dan teras berita }\end{array}$ \\
\hline $\begin{array}{l}\text { Editorial dan } \\
\text { Feature }\end{array}$ & $\begin{array}{l}\text { Membahas teknik tulisan editorial yang merupakan pendapat } \\
\text { editor media dengan mengupasisu-isu terkini. Sedangkan } \\
\text { feature membahas jenis-jenis karangan khas pada majalah. }\end{array}$ \\
\hline $\begin{array}{l}\text { Teknik Penulisan } \\
\text { Berita }\end{array}$ & $\begin{array}{l}\text { Materi ini membahas bagaimana teknik menulis berita di media, } \\
\text { khususnya pada media majalah. }\end{array}$ \\
\hline $\begin{array}{l}\text { Managemen } \\
\text { Penerbitan Pers }\end{array}$ & $\begin{array}{l}\text { Materi ini menyangkut tentang struktur organisasi media, berikut } \\
\text { penjelasan fungsi dan tugas pokoknya. }\end{array}$ \\
\hline Jurnalistik Foto & $\begin{array}{l}\text { Membahas foto-foto jurnalistik yang lazim terdapat dalam media } \\
\text { cetak, serta beberapa contoh foto jurnalistik yang mendapat } \\
\text { penghargaan tingkat dunia. }\end{array}$ \\
\hline Desain Layout & Materi ini berkaitan dengan perwajahan cover majalah. \\
\hline Teknik & Materi ini berkaitan tentang bagaimana menggali data pada \\
\hline
\end{tabular}

2. Pendampingan

Pelatihan dan pendampingan dilaksanakan dengan melakukan kegiatan belajar menmgajar oleh anggota pelaksana. Materi yang disampaikan berupa teoriteori yang harus mereka fahami sebelum melakukan pencarian berita. Pelaksanaan kegiatan tersebut dilaksanakan mulai 24 Januari 2015 sampai 26 Mei 2015, yang dilaksanakan setiap minggunya sesuai dengan jadwal yang telah ditetapkan.

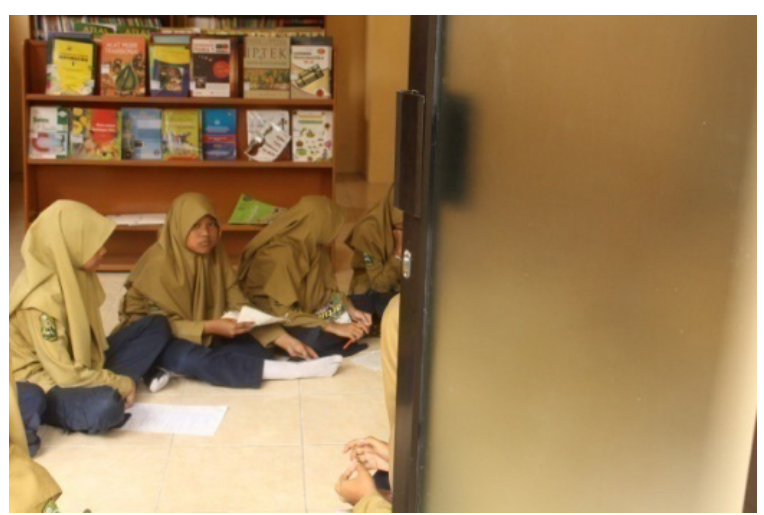

Gb. 2. Suasana Pendampingan Pembuatan Majalah Sekolah di dalam Kelas

\section{Penugasan}

Kegiatan ini bertujuan untuk mengasah ketrampilan Tim Jurnalistik dalam mencari data lapangan. Mereka diberikan penugasan dengan melakukan wawancara, mengambil gambar dengan kamera DSLR, dan membuat layout sederhana. Kegiatan ini dilaksanakan mulai 24 Januari 2015 sampai 26 Mei 2015

\section{Kunjungan}

Kunjungan ke instansi media ini dilakukan pada 7 Mei 2015, dengan tujuan agar siswa-siswi mengetahui instansi media cetak yang terdapat di kota Solo, dan memahami sejarah dan tokoh-tokoh Pers di Indonesia. Kegiatan ini dapat meningkatkan minat siswa-siswi di bidang jurnalistik.

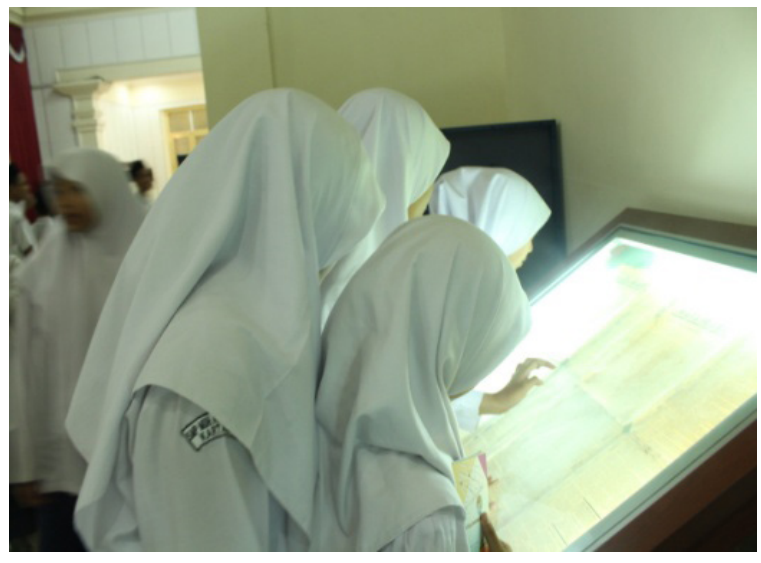

Gambar 3. Suasana Outting Class di Monumen Pers Nasional 


\section{KESIMPULAN}

Setelah dilakukan pemberdayaan wartawan siswa dalam pembuatan Majalah Sekolah Al-Kautsar di SMP Muhammadiyah PK Al-Kautsar Kartasura, kesimpulan yang dapat pelaksana sampaikan adalah:

1. Potensi pelajar Indonesia di bidang jurnalistik sebaiknya terus diasah dan menapatkan perhatian, agar kelak tercipta jurnalis-jurnalis yang berkualitas.

2. Kegiatan pemberdayaan wartawan siswa dalam pembuatan Majalah Sekolah AlKautsar ini memberikan kontribusi yang baik dalam mengelola potensi siswasiswi di bidang Jurnalistik. Mereka yang dahulunya hanya mengambil informasi di internet untuk majalah dinding, sekarang mereka dapat melakukan pengumpulan berita secara mandiri dan menghasilkan tulisn yang memiliki news value.

3. Potensi dari Tim Jurnalistik selalu menunjukkan peningkatan. Potensi ini harus lebih mendapatkan perhatian dan fasilitas yang lebih baik lagi, agar nantinya mereka dapat menghasilkan karya-karya yang juga berpotensial bagi lingkungan sekolah maupun masyarakat sekitar.

4. Eksistensi Majalah Al-Kautsar harus tetap dipertahankan dan diperhatikan secara konsisten. Untuk itu pendampingan dari pihak guru dan pelaksana akan tetap dilaksanakan.

\section{SARAN}

Setelah kegiatan pengabdian berlangsung, ada beberapa saran yang perlu pelaksana berikan untuk kebaikan program kedepan.

1. Kegiatan semacam ini diharapkan dapat berlangsung lapis generasi. Sehingga aka nada regenerasi wartawan sekolah.

2. Dalam kegiatan tersebut, pelaksana kedepan dapat melakukan studi banding pada majalah sekolah lain yang sudah rutin terbit.

\section{PERSANTUNAN}

Kami selaku pelaksana mengucapkan terimkasih kepada LPPM UMS yang telah mendanai kegiatan pemberdayaan wartawan siswa tersebut sehingga dapat berjalan dengan baik. Kami ucapkan terimakasih juga kepada kepada pihak SMP Muhammadiyah PK AlKautsar Kartasura yang telah memberikan izin dilaksanakannya pendampingan pembuatan Majalah Al-Kautsar. Yang paling penting, kami ucapkan selamat kepada para siswa yang telah berpartisipasi aktif dalam kegiatan ini.

\section{DAFTAR PUSTAKA}

Dewi, A. M. (2013). MAJALAH DINDING SEBAGAI IMPLEMENTASI KEMAMPUAN MENULIS CERPEN SISWA YANG MENGIKUTI EKTRAKURIKULER JURNALISTIK DI SMP N 4 SINGARAJA. Jurnal Jurusan Pendidikan Bahasa dan Sastra Indonesia , 1 (1), 1-15.

Hidayati, I. N. (2014). MASKOT UDI DAN BANDI UNTUK REDESAIN MAJALAH SEKOLAH MTS AL-IHSAN KRIAN SEBAGAI PENGENALAN IKON KOTA SIDOARJO. Jurnal Pendidikan Seni Rupa , 2 (2), 2.

Miyono, N. (2011). KEPUASAN DAN LOYALITAS PELANGGAN PADA SEKOLAH DASAR SWASTA UNGGUL DI SEMARANG. Jurnal Dinamika Sosial Ekonomi , 7 (2), 148-163.

Santoso, H. (2007). MAJALAH DINDING SEBAGAI MEDIA UNTUK MENINGKATKAN KEMAMPUAN MENULIS DAN BUDAYA BACA SISWA. Malang: Perpustakaan Unversitas Negeri Malang . 
Saputra, A. W. (2015). PENGEMBANGAN BLOG MENULIS BERITA UNTUK MAJALAH SEKOLAH SEBAGAI MEDIA PEMBINAAN EKSTRAKURIKULER JURNALISTIK BAGI SISWA SMA. Jurnal Kembara , 1 (2), 117-124.

Wiastra, I. G., Rasna, W., \& Astika, I. M. (2015). PEMBINAAN DAN MANAJEMEN PRODUKSI MAJALAH SEKOLAH PADA EKSTRAKULIKULER JURNALISTIK DI SMA NEGERI 4 SINGARAJA. JJPBS , 3 (1), 1-13. 